\title{
Psychosocial Rehabilitation in Schizophrenia: Beginnings in Acute Hospitalization
}

\author{
Nancy A. Mann, Rajiv Tandon, Joann Butler, Margo Boyd, \\ William H. Eisner, and Maureen Lewis
}

\begin{abstract}
Schizophrenic patients discharged from acute inpatient settings are often unprepared to function outside the hospital, leading to recidivism and frequent rehospitalization. Social skills training programs addressing this need have hitherto only been developed for use in outpatient or long-term inpatient settings. We describe the development of a social skills training program for application in a short-term acute inpatient unit. Nursing coordinates the program, which is designed for a 3 to 4 week hospitalization and is delivered in an open group setting. The training program emphasizes communication skills, problem solving, affect identification, needs recognition, and social relatedness. The program uses group discussions, writing tasks, physical activity, education, role-play, feedback, and assignments. Goals include assessment of individual deficits, inculcation of awareness that life-objectlves can be identified and achieved, assistance with transition to postdischarge living situation or outpatient treatment program, and development of awareness of one's roles and responsibilities. The evolution and present structure of the program are described and four representative lessons are detailed.

Copyright (C) 1993 by W.B. Saunders Company
\end{abstract}

$\mathbf{T}$ HERE IS A general consensus that structure, medication, a protective nonthreatening environment, and family psychoeducation comprise essential ingredients of any state-of-the-art inpatient treatment package for acute schizophrenic patients. The role of additional individual psychological/psychoeducational treatment is controversial. The crisis intervention and symptom reduction models that currently prevail in the acute inpatient treatment of schizophrenia do not adequately address the problems in social skills deficits and social adjustment that often precipitated the hospitalization in the first place. Mobilization for

From the Schizophrenia Program and the Department of Psychiatric Nursing, University of Michigan Medical Center, Ann Arbor, MI.

Address reprint requests to Nancy A Mann, RN, BSN, University of Michigan Medical Center, Ann Arbor, MI 48109-0120.

Copyright (C) 1993 by W.B. Saunders Company 0883-9417/93/0703-0006\$3.0010 discharge is often perfunctory and patients frequently return to the community poorly prepared to deal with environmental stressors that constitute part of their daily lives. This often leads to recidivism, frequent rehospitalizations (revolving door), treatment noncompliance, a sense of hopelessness, and a poor quality of life.

Schizophrenic patients in acute inpatient settings present a dilemma in terms of the nature of appropriate psychological/psychosocial treatment (Maves \& Schulz, 1985; Drake \& Sederer, 1986a; Wong, Flanagan, Kuehnel, Liberman, Hunnicutt, \& Adams-Badgett, 1988). Experts agree that intense, uverstimulating psychotherapies have no role in the acute inpatient treatment of schizophrenia and, in fact, may be harmful and promote regression because they are overly intrusive and ignore the patient's need for support, education, and mastery (Gunderson, Frank, Katz, Vannicelli, Frosch, \& Knapp, 1984; Drake \& Sederer, 1986b). In their review of inpatient psychosocial 
treatments, Drake and Sederer (1986b) prescribe the following characteristics for inpatient psychotherapy of schizophrenia: (1) the goals should be modest and well-defined; (2) interactions with the patient should be gentle and supportive; and (3) attention should be paid to long-term adjustment as well as to short-term symptom removal.

Social skills training is one form of psychological treatment with the above characteristics (Wallace, Nelson, Liberman, Aitchison, Lukoff, Elder, et al., 1980). It is also one of the few treatments that has been reported to be effective in improving the coping skills and increasing the social competence in schizophrenic patients, which are essential in reducing recidivism and improving outcomc (Liberman, Massel, Mosk, \& Wong, 1985). Although sucial-skills training programs for schizophrenic patients are available for use in outpatient and long-term inpatient settings, no such systematic treatment package exists for use in acute inpatient settings where a majority of schizophrenic patients are hospitalized when in need of inpatient treatment.

Although a comprehensive program that can identify and remedy the social-skills deficits in any given schizophrenic patient is clearly not possible in the course of a brief inpatient hospitalization (particularly with the decreasing lengths of stay), there is a clear need to develop a program that improves the ability of patients to cope with stressors they will encounter immediately following discharge. There are additional reasons to develop a modified social-skills training program for use in an acute inpatient setting: (1) the acute inpatient unit provides a unique opportunity to provide necessary care in terms of patient motivation and availability (as they present in a crisis and are more accepting of treatments that they might not accept or seek when they are out of the crisis); and (2) in addition to providing custodial care, staff on an inpatient unit are often unsure as to how to provide therapeutic, nonstressful, structured activity schedules for schizophrenic inpatients that meet the criteria delineated by Drake and Sederer (1986b).

We have developed such a social-skills training program for application in a short-term inpatient unit. The program has evolved over the past 4 years into its present form, requiring progressive adaptation to the continual shortening in the lengths of stay and increased acuity of patient mix. In this article, we describe the program's goals, structure/format, techniques, staff and patient experience, and provide a rationale for implementing the program in other acute care facilities for schizophrenic inpatients.

\section{PROGRAM SETTING}

The setting for the program is a 22-bed adult psychiatry inpatient unit at the University of Michigan Medical Center where the Schizophrenia Program is based. The unit is staffed by an interdisciplinary team of mental health professionals, trainees, and support staff. With the initiation of the Inpatient Schizophrenia Program 5 years ago, it was decided to develop a comprehensive, stateof-the-art, treatment package optimally suited for acute schizophrenic inpatients. Other components of this treatment package include appropriately comprehensive diagnostic assessment, resource and network evaluation, provision of structure, and a nonthreatening protective environment, optimizing the medication regimen, attention to other medical needs and substance abuse, family psychoeducation, and appropriate social interventions. Because they are not the focus of this article, their details will not be discussed. To remedy the social skills deficits of most schizophrenic patients at the time of discharge that led to recidivism and frequent rehospitalization, we adapted principles of social skills training for use in our acute inpatient setting. The program was developed and administered by a team of clinical nurses. Since its inception, about 250 patients have received a version of this social-skills training program.

Schizophrenic inpatients participating in the program range in age from 18 to 60 years (mean age $=34 \pm \mathrm{SD} \pm 9$ years), $60 \%$ male, with a mean duration of illness of $10 \pm 8$ years. There is an assorted payor mix, with about $50 \%$ of patients covered by Medicaid, $30 \%$ by private insurance, and the remaining $20 \%$ with other or no coverage. Patients are usually admitted during a psychotic episode, with about $10 \%$ to $15 \%$ experiencing the onset of schizophrenia. Our average length of stay has declined from 34 days (in 1987) to the current 20 to 22 days (a factor necessitating changes in the social skills training program).

The vast majority of discharge referrals are made to outside agencies and practitioners. Conti- 
nuity of care and use of community-based resources, therefore, are influenced by many factors external to our system. Our lack of control over many aspects of the discharge process significantly limits our ability to achieve good continuity of care and stable transition to the outpatient setting. Consequently, there is a greater emphasis on the patient's ability to connect with and avail themselves of various treatment and social agencies. Effective social skills training enhances the patient's success in complying with discharge treatment plans.

\section{PROGRAM DESCRIPTION AND OBJECTIVES}

Patients participate daily in the social-skills training program from admission to discharge. The social-skills training program is administered in a group setting. Groups consist of four to six patients and two staff members who meet for 30 to 45 minutes, 5 to 7 times a week. At each group session, a specific lesson plan is reviewed. Instructor and patient materials have been developed for each lesson. Objectives, procedures, and options are listed for each lesson plan in an instructor manual. Handouts, paper, pencil, and other necessary supplies for the lesson plan of the day are provided. Both expressive and directive techniques are used. Specific techniques used include instruction in lecture format, group discussion, writing, role-play, feedback, physical activity, and assignments. The list of lessons is detailed in Table 1.

All patients receive lessons in Table $1 \mathrm{~A}$ in the order in which they are listed. Most patients receive several lessons from Table 1B, although not necessarily in the order in which they are listed. Depending on the length of stay, patients may receive one or more lessons from Table 1C. Flexibility is an important aspect of this program. The lessons can be adapted to suit the needs of higher functioning versus lower functioning patients, and can be adjusted in terms of the length of stay. Many lesson plans have multiple formats and choices, from which an appropriate format can be selected to suit the needs of the particular group.

Two staff nurses are necessary to conduct these groups: a leader and coleader. The leader prepares the room for the group, welcomes members as they arrive for class, and leads the group interaction. The coleader is responsible for getting members to class, dealing with distractions, and working individually with patients who need special assistance. Two additional staff nurses are also trained in the
Table 1. List of Lessons

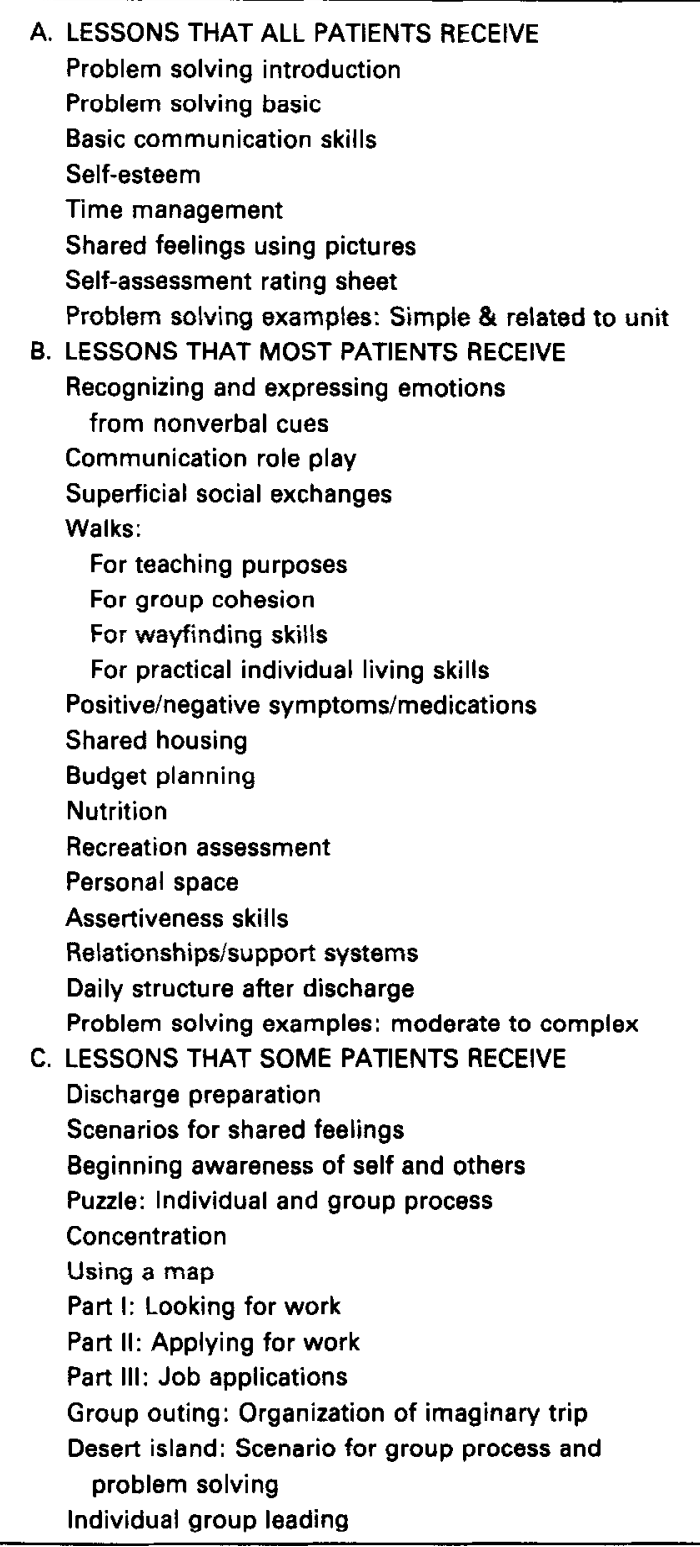

method and content of the social-skills program and can step in as back-ups when one of the leaders is absent.

The leader meets individually with each new member to orient and prepare the patient for the group. Each group generally goes through three stages of evolution: (1) assessment and engagement (basic skills are taught in this phase), (2) midphase (these skills are applied to problems and situations on the inpatient unit and basic skills are retaught as necessary), and (3) predischarge (these skills are applied to actual or anticipated postdis- 
charge problems and situations). Each stage lasts for about 1 week, although this can vary according to the symptom status and level of function of group members.

The overall objectives of the group are: (1) to develop a sense of bonding and decrease the sense of isolation and loneliness; (2) to inculcate the awareness that problems experienced by the patient can be analyzed and that goals can be developed and achieved; (3) to identify individual deficits and begin development of strategies to address them; (4) to assist the process of transition to the postdischarge setting in terms of housing, and the outpatient treatment program; and (5) to promote the development of a sense of family role and responsibility.

\section{PHASES OF GROUP PROGRESSION}

\section{Member Preparation and Introduction}

Before participating in the groups, staff members meet individually with each patient to apprise them of the nature of the group. Patients receive an introductory handout and are informed that they are part of a distinct group that will participate in a series of classes conducted by two instructors. A formal connection is thus made with each patient and the role of the nurse-instructor as a teacher is emphasized. This meeting is designed to prepare the patient for the group, establish a clear set of expectations (such as being on time), and set the group as being distinct from other ward activities in the patient's mind.

\section{Assessment and Engagement}

The major objective in this phase is to foster a feeling of comfort and group cohesion. In the first few days, patients are encouraged to come, even for a few minutes, so that they can begin to make connections and develop a sense of belonging. $\mathrm{Pa}$ tients receive the lessons in the order listed in Table 1A, basic problem solving summarized in Table 2A, simple communication skills and selfesteem in Table 3, time management in Fig 1, affect recognition and shared feelings using pictures in Table 4 and Fig 2, and self-assessment. Many of these skills are used throughout the program.

The emphasis in the first few days is on patient attendance and presence in the group. During this time, some deviant behavior is tolerated; for ex-
Table 2. Lessons in Problem Solving

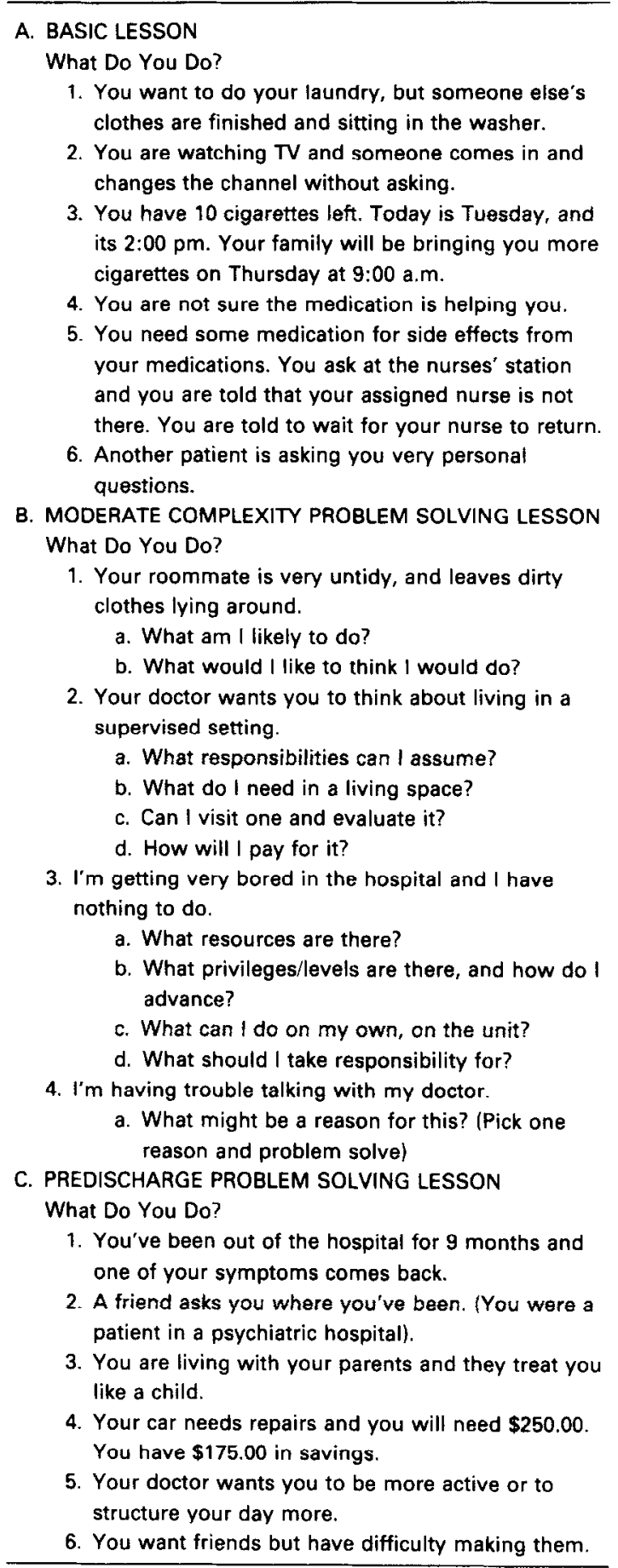

ample, members are allowed to pace, drink fluids, and express some delusional material. We have found that permitting patients to briefly verbalize their delusional thoughts and then redirecting them enables them to maintain self-control and focus on the topic being discussed. If members become too 
Table 3. Self Esteem

\begin{tabular}{|c|c|c|c|}
\hline OBJECTIVES & PROCEDURE & ASSESS FOR & $\begin{array}{l}\text { TOPICS FOR } \\
\text { DISCUSSION }\end{array}$ \\
\hline $\begin{array}{l}\text { Identify value system } \\
\text { Set goals } \\
\text { Share communication }\end{array}$ & $\begin{array}{l}\text { Patients are given paper and } \\
\text { pencils and told to write } \\
\text { down what they need for } \\
\text { good self esteem } \\
\text { Each list is read and } \\
\text { discussed by group }\end{array}$ & $\begin{array}{l}\text { Comfort and a written } \\
\text { assignment } \\
\text { Ability to abstract } \\
\text { Their own self awareness } \\
\text { and value system } \\
\text { Ability to communicate and } \\
\text { discuss }\end{array}$ & $\begin{array}{l}\text { Explanations of their lists. } \\
\text { Ask each patient to review } \\
\text { and list how many of the } \\
\text { items from the original list } \\
\text { they already have. Discuss } \\
\text { areas not covered and } \\
\text { suggest these as future } \\
\text { goals. } \\
\text { Identify these items as things } \\
\text { valued, which collectively } \\
\text { make up a value system. } \\
\text { The importance of a value } \\
\text { system for positive self- } \\
\text { esteem. }\end{array}$ \\
\hline
\end{tabular}

NOTE. Variations on Topics for Discussion include:

If patients in the group are low functioning, ask the question, "What do I need to feel good about myself?"

Higher functioning patients may easily digress into discussion of loss of self esteem due to psychiatric illness. They may be able to explore feelings and perceptions.

Patients frequently do better if answers are listed on a blackboard.

For emphasis on goal setting and personal objectives, keep work individualized. For instance, don't use a blackboard. Have them keep separate, written lists and encourage exploration of how future goals could be met. Keep your own record for possible future classes. Items from this list could be used for future problem solving.

For emphasis on group work, have patients call out answers and, if the group agrees, write them directly on the blackboard.

disruptive, they are thanked for their efforts and permitted to leave with the request that they try again the next day. Appropriate behavioral expectations and patient participation increases as the group progresses and the patients' symptoms decrease.

Because the emphasis in this phase is to foster group cohesion and a sense of safety, activities such as patient role-play, complex tasks, and intrusive personal questions are avoided. The lesson on affect recognition and shared feelings (Table 4 and Fig 2) is particularly powerful in fostering group cohesion. In this lesson, patients are asked to pick a picture from several placed on the table (Fig 2) that best expresses the way they feel. In addition to being a fairly safe way of expressing oneself, group members begin relating to each other via the pictures, and develop an interest in the person choosing a picture. Eye contact often improves and the frequency of interaction between group members increases.

\section{Midphase}

With increasing group cohesion and improvement in the clinical status of the group members, more complex tasks and lesson plans are used as shown in Table 1B and C. Depending on the level of functioning and rate of progress of the group, lessons from the previous phase may have to be reviewed. In the midphase, basic problem-solving skills previously learned (Table $2 \mathrm{~A}$ ) are applied to unit situations (Table 2B) and assignments are prescribed to apply communication and other basic skills to unit behaviors. Other techniques, such as patient role-play, feedback, group discussion, and assignments, begin to be used in this phase. Group walks with one of the patient-members as the group leader also occur in this phase.

\section{Predischarge Phase}

In the predischarge phase, these basic skills are applied to situations and potential problems that can be anticipated following discharge. Patients' abilities to comprehend and problem-solve specific difficulties and stressors that can be anticipated in their postdischarge life-situations are assessed; specific strategies to address these are discussed. As in the previous stages, the level of function and the specific needs of the group members dictate the content and complexity of the lessons. The materials and options for each lesson plan permit this flexibility. Role-play (both staff and patient), feed- 


\begin{tabular}{|c|c|c|}
\hline \multicolumn{3}{|l|}{$\begin{array}{l}\text { Work } \\
\text { Play/Relaxation } \\
\text { Eating } \\
\text { Sleeping } \\
\text { Hygiene } \\
\text { Socializing } \\
\text { Other activities }\end{array}$} \\
\hline \multicolumn{3}{|c|}{$\begin{array}{l}\text { Decide how big a slice each } \\
\text { would be. How would your } \\
\text { pie look? }\end{array}$} \\
\hline \multicolumn{3}{|c|}{ 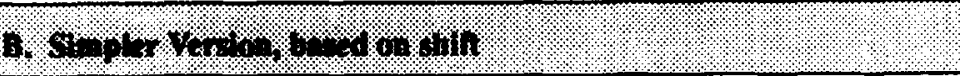 } \\
\hline $7: 30 \mathrm{am}-4: 00 \mathrm{pm}$ & $\begin{array}{r}7: 30 \mathrm{am} \\
8: 00 \mathrm{am} \\
9: 00 \mathrm{am} \\
12: 00 \mathrm{pm} \\
4: 00 \mathrm{pm}\end{array}$ & $\begin{array}{l}\text { Get up. Shower. Get Dressed } \\
\text { Breakfast. Brush teeth. Take medication } \\
\text { Go to Day Treatment } \\
\text { Eat lunch } \\
\text { Finish in Day Treatment }\end{array}$ \\
\hline $4: 30 \mathrm{pm}-11: 00 \mathrm{pm}$ & $\begin{array}{l}4: 00 \mathrm{pm} \\
4: 30 \mathrm{pm} \\
5: 00 \mathrm{pm} \\
6: 00 \mathrm{pm} \\
6: 30 \mathrm{pm} \\
7: 00 \mathrm{pm} \\
8: 00 \mathrm{pm}\end{array}$ & $\begin{array}{l}\text { Walk home. } \\
\text { Relax. } \\
\text { Help with cooking. } \\
\text { Eat supper. Take medication } \\
\text { Help with dishes. } \\
\text { Do laundry or clean. } \\
\text { Watch TV or do hobbies. }\end{array}$ \\
\hline $11: 00 \mathrm{pm}-7: 30 \mathrm{am}$ & $\begin{array}{l}11: 00 \mathrm{pm} \\
11: 30 \mathrm{pm}\end{array}$ & $\begin{array}{l}\text { Gel ready for bed. Brush teeth. } \\
\text { Go to bed. }\end{array}$ \\
\hline
\end{tabular}

Fig 1. Time management.

back, group discussion, unit and on-pass assignments are the major techniques used. Application of problem-solving skills in this stage of the group is illustrated in Table $2 \mathrm{C}$.

\section{EXPERIENCE, EVOLUTION, AND FUTURE WORK}

This program has gradually evolved over the past 4 years. It has had to adapt to the shorter lengths of stay and the increasing acuity of new patients. Patients have related well, and significant group cohesion has been observed. Patients identify with one another and seek out fellow group members while on the unit. They tolerate this group very well. An improvement in unit behaviors and the overall milieu has been seen, and conflicts are resolved much more quickly. Patients re- port the considerable benefit of the group in terms of helping them deal with problematic situations in the immediate postdischarge phase. Unless followed by some form of outpatient social-skills training, these gains are not sustained indefinitely. However, during readmissions former patients often inquire about rejoining this group.

Staff have been impressed by the improvement in unit milieu and the sense of hope and optimism fostered by the group in patients, their families, and the staff. The group also has had a positive impact on staff morale as it reinforces a more active role of the nurse as a teacher/treater. A significant positive outcome has been observed in the behavior of patients as a consequence of the group. A controlled study (comparing 6-month, 1-year, 


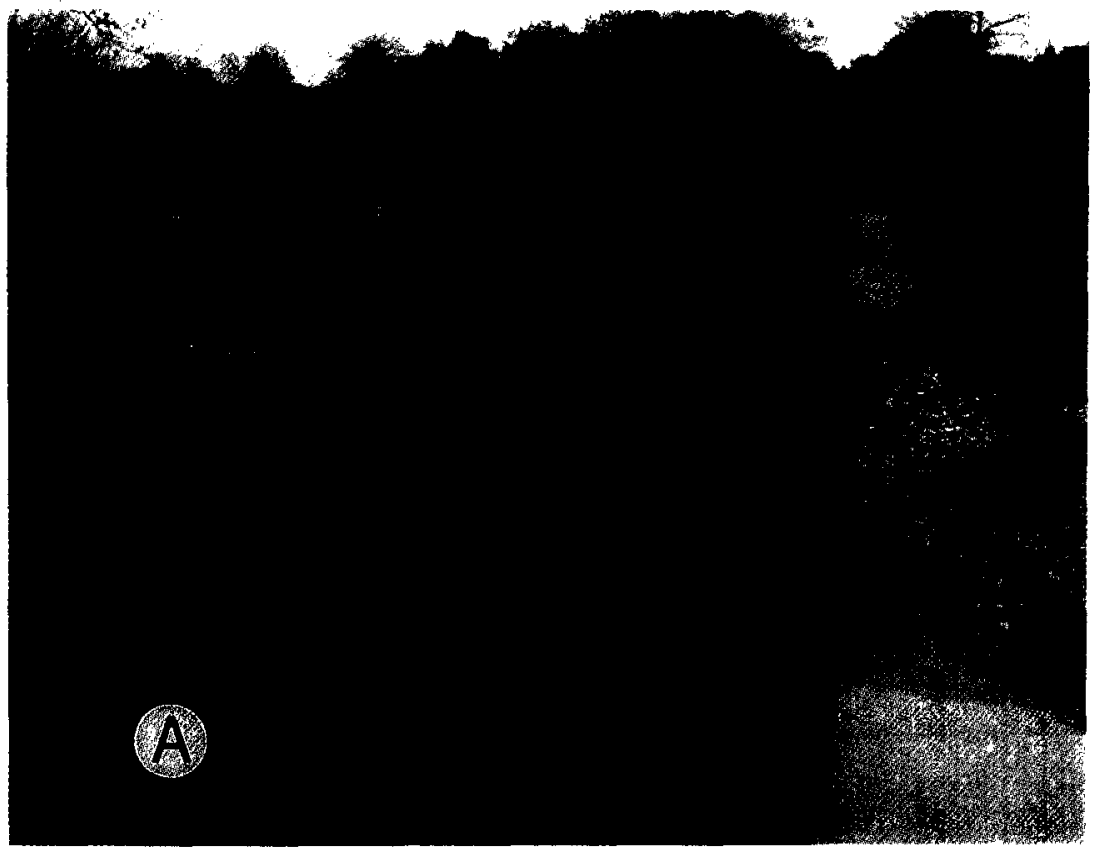

Fig 2. Examples of pictures used for lesson on affect recognition and shared feolings using pictures with selected pationt comments.

I'm stuck in a maze and can't find my way out.

I'm lost and alone.

It's like someone else is calling the shots and you can't see where you're going.

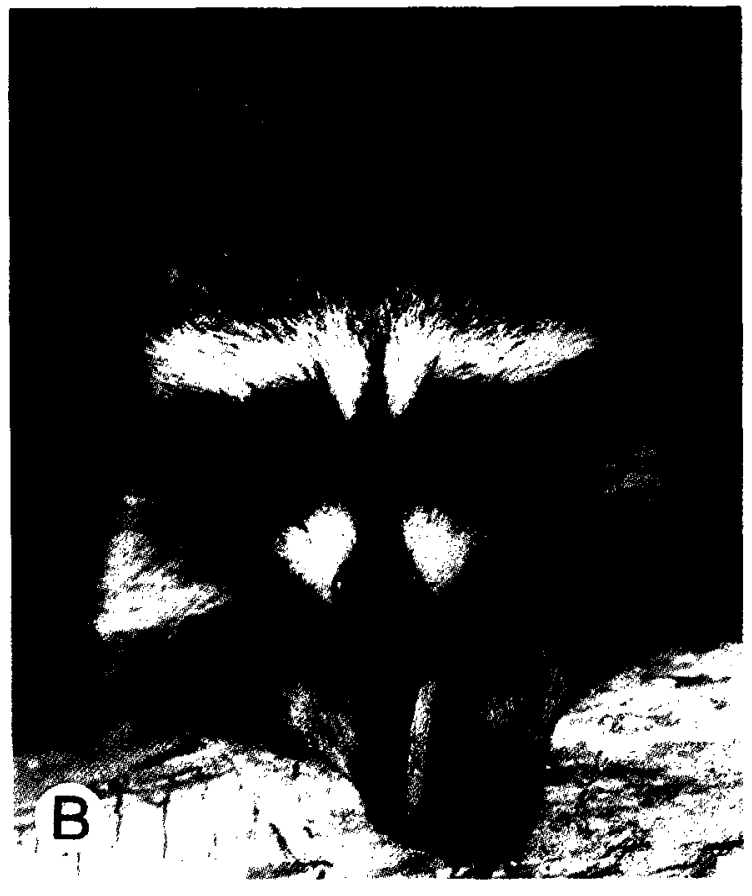

That's mel That's the way I am.

Sometimes when you're small you need to hide behind something bigger.

Ho's crying.

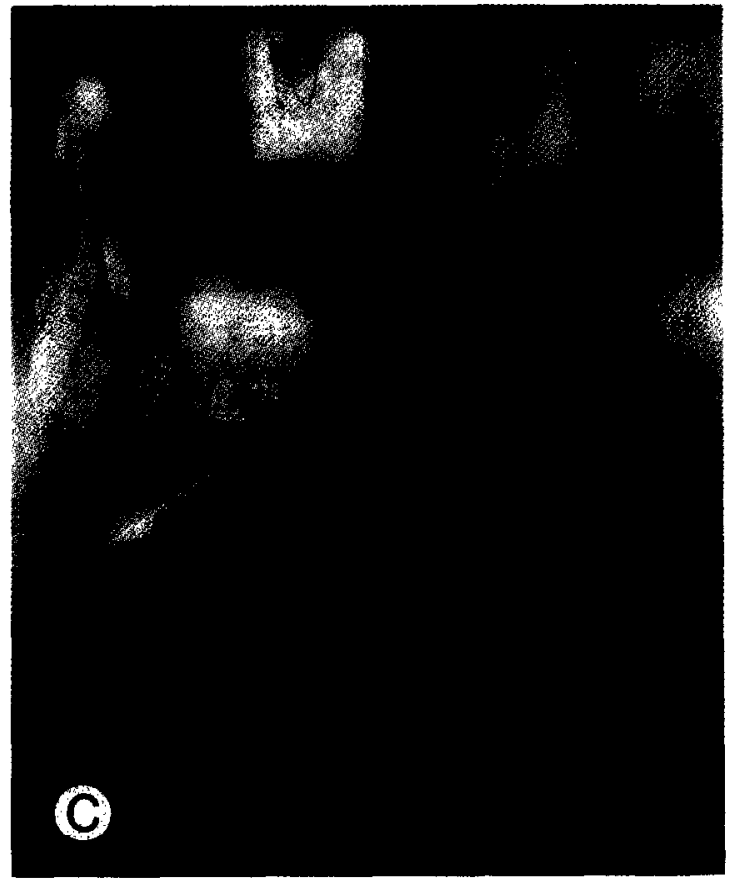

It shows loneliness.

I'm lost.

I'm deep, down at the bottom. 
Table 4. Shared Feelings Using Pictures

\begin{tabular}{|c|c|c|c|}
\hline OBJECTIVES & PROCEDURE & ASSESS FOR & $\begin{array}{l}\text { TOPICS FOR } \\
\text { DISCUSSION }\end{array}$ \\
\hline $\begin{array}{l}\text { Patient will be able to } \\
\text { identify feelings through } \\
\text { looking at and describing } \\
\text { pictures. } \\
\text { Patient will be able to } \\
\text { interpret the picture to } \\
\text { group members. } \\
\text { Patient will begin interacting } \\
\text { with group members. } \\
\text { Group cohesiveness will } \\
\text { occur. }\end{array}$ & $\begin{array}{l}\text { Put pictures on a table } \\
\text { Encourage patients to pick } \\
\text { one or two pictures which } \\
\text { reflect their mood at the } \\
\text { present time. } \\
\text { Have each person hold up } \\
\text { and interpret their picture } \\
\text { for the group. }\end{array}$ & $\begin{array}{l}\text { Interest and ability with } \\
\text { which patients engage in } \\
\text { the task, e.g. some patients } \\
\text { cannot connect with } \\
\text { feelings or are very } \\
\text { concrete. Rather than say } \\
\text { "I feel lonely", they might } \\
\text { say "I like flowers, so I } \\
\text { picked a rose." } \\
\text { Comfort level in sharing } \\
\text { information/feelings } \\
\text { The place that emotions } \\
\text { have in patient's value } \\
\text { system. } \\
\text { Degree to which patients } \\
\text { begin making eye contact } \\
\text { and talking with each } \\
\text { other. }\end{array}$ & $\begin{array}{l}\text { 1. Explanations of the } \\
\text { pictures. } \\
\text { 2. Are individual's pictures } \\
\text { validated by others in the } \\
\text { group? If not, why? } \\
\text { 3. The value of knowing } \\
\text { your own feelings and of } \\
\text { being able to share them } \\
\text { with others. }\end{array}$ \\
\hline
\end{tabular}

NOTE. Variations on topics for Discussion include:

If people in the group are low functioning and cannot choose a picture, choose one for them. Describe how that picture represents them, i.e., mood, affect or behavior.

If people are high functioning, advance to discussion about variation in interpretation, e.g." "this picture makes me feel sad" or "this makes me feel calm." This leads you to a need for validation of interpretation, "You look angry, are you?"

and 2-year outcomes of patients randomly assigned to a skills group or a control social group) to evaluate the efficacy of this group in a systematic manner has been developed and is ongoing.

\section{CONCLUSIONS AND FUTURE DIRECTIONS}

Restricting the objectives of brief hospitalization to symptom reduction and crisis intervention in the face of limited aftercare services, undermines the tenuous gains that schizophrenic patients make by the time of their discharge. This approach fosters recidivism and the recurrent cycle of hospitalizations often seen in schizophrenic patients and contributes to the high human and economic costs of schizophrenia. The poor functional skills of many schizophrenic patients leaves them poorly equipped to deal with the stressors of daily life following discharge, preventing them from using the limited aftercare services that do exist. Social skills training groups can equip schizophrenic patients to better cope with these stressors and obtain access to necessary aftercare and other social services. As our experience shows, a group skillstraining strategy can be successfully adapted for schizophrenic patients in an acute inpatient setting.

Social-skills training groups are well-tolerated and liked by patients. Staff members have also reported their efficacy in improving patient coping abilities and social skills. Preliminary studies indicate that, although the gains may be temporary, they are crucial in improving the likelihood of a smooth transition to the outpatient setting and minimizing the chance of immediate rehospitalization. For retention and further refinement of these newly acquired social skills, postdischarge training and practice are essential. The objective of our inpatient skills-training program is not to dramatically cure or eliminate social skills deficits, but to lay the groundwork for continued social-skills improvement and positive long-term adjustment. In settings where outpatient social-skills training is available, an inpatient component facilitates the transition from inpatient to outpatient status. Introducing the patient to social-skills training during the inpatient stay, when the patient and his or her family are often in crisis, increases the possibility that the patient may be receptive to new treatments.

Additionally, this treatment fosters a sense of hope and autonomy in the patient without being intrusive or overly stressful. It also promotes greater responsiveness to other biological and psy- 
chosocial treatment approaches during both the inpatient and aftercare phases of treatment. Controlled research studies to more accurately evaluate the impact, utility, and wider applications of this effort are ongoing.

\section{ACKNOWLEDGMENT}

The authors thank Marge Calarco, PhD, RN, JoAnn Goodson, BS, RN, Claudia Wessels, BS, and Esther Poku-Kankam, for their help in conducting the study and in preparation of the manuscript.

\section{REFERENCES}

Drake, R.E., \& Sederer, L.I. (1986a). The adverse effects of intensive treatment of chronic schizophrenia. Comprehensive Psychiatry, 27, 313-326.

Drake, R.E., \& Sederer, L.I. (1968b) Inpatient psychosocial treatment of chronic schizophrenia: Negative effects and current guidelines. Hospital and Community Psychiatry, 37, 897-901.

Gunderson, J.G., Frank, A.F., Katz, H.M., Vannicelli, Frosch, \& Knapp. (1984). Effects of psychotherapy in schizophrenia, II: Comparative outcome of two forms of treatment. Schizophrenia Bulletin, 10, 564-598.

Liberman, R.P., Massel, H.K., Mosk, M.D., \& Wong, S.E. (1985). Social skills training for chronic mental patients. Hospital and Community Psychiatry 36, 396403.

Maves, P.A., \& Schulz, J.W. (1985). Inpatient group treatment on short-term acute care units. Hospital and Community Psychiatry, 36, 69-73.

Wallace, C.J., Nelson, C.J., Liberman, R.P., Aitchison, Lukoff, Elder, et al. (1980). Social skills training with schizophrenic patients. Schizophrenia Bulletin, 6, 4263.

Wong, S.E., Flanagan, S.G., Kuehnel, T.G., Liberman, Hunnicutt \& Adams-Badgett. (1988). Training chronic mental patients to independently practice personal grooming skills. Hospital and Community Psychiatry, 39, 874879. 